\title{
As concepções de universitários ingressantes e concluintes do curso de ciências biológicas da Universidade Federal de Santa Maria (UFSM) relacionadas a questões de ciência e tecnologia
}

The conceptions of freshmen and graduating students of Biological Sciences at Federal University of Santa Maria (UFSM) related to science and technology issues

\author{
Micheli Bordoli Amestoy*1, Karine Bueno do Nascimento², \\ Luiz Caldeira Brant de Tolentino-Neto ${ }^{3}$
}

\begin{abstract}
${ }^{1}$ Bacharel e Licenciada em Ciências Biológicas, Mestranda do Programa de Pós-Graduação Educação em Ciências:
Química da Vida e Saúde, Universidade Federal de Santa Maria, Santa Maria, Brasil

${ }^{2}$ Licenciada em Educação Física, Universidade de Cruz Alta, Mestranda do Programa de Pós-Graduação

Educação em Ciências: Química da Vida e Saúde pela, Universidade Federal de Santa Maria, Santa Maria, Brasil

${ }^{3}$ Doutor em Educação, Universidade Federal de Santa Maria, Santa Maria, Brasil
\end{abstract}

\begin{abstract}
Resumo
Oobjetivo dessa pesquisaé, a partir da Voz de universitários ingressantes e concluintes do curso de Ciências Biológicas da UFSM, descrever suas concepções e posicionamentos diante de questões sobre Ciência e Tecnologia. Utilizou-se uma adaptação do questionário internacional de pesquisa intitulado The Relevance of Science Education (ROSE). O resultado encontrado revela uma inquietação frente à identidade profissional construída pelos universitários durante a formação acadêmica, independente das habilitações escolhidas - bacharelado ou licenciatura. Constatamse universitários ingressantes mais otimistas do que os colegas concluintes, o que desencadeia uma discussão sobre reformas curriculares que colaborem na construção de uma identidade profissional condizente com a escolha da futura profissão.
\end{abstract}

Palavras-chave: ROSE. Ciências Biológicas. Ciência e Tecnologia. Identidade Profissional.

\begin{abstract}
The aim of this research is from the Voice of freshmen students and graduating in Biological Sciences in the UFSM, describe their conceptions and positions on issues of Science and Technology. We used an adaptation of the international research titled The Relevance of Science Education (ROSE). The results obtained revealed an unrest ahead to the professional identity built by the college students during the academic education, regardless of qualifications chosen - Bachelor or Licensee Degree. The freshmen are more optimistic than the students in the final of the Course, which triggers a discussion about curricular reforms to collaborate with the construction of a professional identity according to the choice of future profession.
\end{abstract}

Keywords: ROSE. Biological Science. Science and Technology.

*micheliamestoy@gmail.com 


\section{Introdução}

$\mathrm{M}$ uitas de nossas tarefas cotidianas são intermediadas por elementos de Ciência e Tecnologia (C\&T). Segundo Santos e Mortimer (2002, p.02) "vivemos hoje em um mundo notadamente influenciado pela ciência e tecnologia. Tal influência é tão grande que podemos falar em uma autonomização da razão científica em todas as esferas do comportamento humano". Refletir como estas relações estão estabelecidas e suas implicações na sociedade é fundamental, uma vez que interfere diretamente em nossas vidas.

Nesta perspectiva, Auler e Delizoicov (2006) salientam que, para uma leitura crítica da realidade, torna-se fundamental uma compreensão igualmente crítica sobre as interações entre Ciência, Tecnologia e Sociedade (CTS), considerando que a dinâmica social contemporânea está fortemente marcada por sua presença. Porém, é notável a carência de currículos - tanto na educação básica quanto no ensino superior - que tenham como base o incentivo a essa compreensão crítica e não só as relações, mas as interações que existem entre CTS. Segundo Angotti e Auth (2001, p. 19):

Nos planejamentos escolares, principalmente no que tange aos objetivos de cada disciplina ou área de estudo, são usuais expressões relacionadas à idéia de tornar os alunos mais ativos ou criativos. No entanto, pais e professores, formadores de opinião pública, vêm insistindo na excessiva passividade e até na alienação de jovens e adolescentes. Dificilmente são promovidas discussões que levam em conta a finalidade de ser criativo, a quem esta contribuição vai beneficiar, ou no que esta criatividade vai desencadear.

Neste entendimento, Freire (1980, p. 26) salienta que a conscientização implica em, "que ultrapassemos a esfera espontânea de apreensão da realidade, para chegarmos, a uma esfera crítica na qual a realidade se dá como objeto cognoscível e na qual o homem assume uma posição epistemológica". Conforme a atual carência nos currículos com relação à compreensão e conscientização crítica de assuntos ligados a $C \& T$, fazem-se necessárias pesquisas que se preocupem com o que pensam os jovens sobre esses assuntos, incentivando discussões e reflexões em torno desta problemática.

Neste sentido a Universidade de Oslo, na Noruega, desenvolveu o projeto intitulado The Relevance Of Science Education (ROSE), que tem como tradução A Relevância do Ensino de Ciência, que envolve mais de 45 países, a fim de realizar pesquisas comparativas internacionalmente com a finalidade de conhecer as prioridades de atitudes, interesses, experiências, posicionamentos, valores, percepções sobre ciência e tecnologias, planos futuros e envolvimento com as questões ambientais de estudantes na faixa dos 15 anos (OGAWA; SHIMODE, 2004).

Este projeto parte do princípio de escutar "a voz do estudante", termo esse que tem sido considerado como elemento de comunicação transformadora (JENKINS, 2006), uma vez que após conhecer as percepções e posicionamentos dos investigados sobre os temas já citados, pode-se estabelecer um diálogo que busque a problematização destes assuntos.

Esta gama de compreensões pode ser obtida através de um questionário. O questionário traduzido e adaptado no Brasil (TOLENTINO-NETO, 2008) avalia o interesse dos alunos em determinados assuntos ligados às ciências da natureza: Química, Física e Biologia. Cada afirmativa é mensurada em uma escala Likert de quatro pontos. A proposta original tem como foco estudantes da faixa etária de 15 anos de idade, sendo que no Brasil esses alunos encaixam-se no 9 $^{\mathbf{o}}$ ano do Ensino Fundamental e no $1^{\circ}$ ano do Ensino Médio, tornando-se um material de grande contribuição para que se trace não só tendências mas, também, prováveis caminhos transformadores para o Ensino de Ciências.

Levando em consideração as problemáticas que envolvem C\&T em seus diversos aspectos e tendo como interesse escutar "a voz do estudante" sobre esta temática, surgiu a seguinte questão problematizadora: quais os posicionamentos de estudantes de biologia sobre ciência e tecnologia? Nossa preocupação com as opiniões destes profissionais deve-se ao fato de que têm a capacidade de intervir como mediadores do conhecimento relativo à ciência e à tecnologia de forma crítica, tanto na prática da pesquisa quanto no ensino. Desta forma, o objetivo deste estudo é traçar um perfil comparativo entre ingressantes e concluintes do curso de Ciências Biológicas do ano de 2013, frente às temáticas de C\&T.

\section{Metodologia}

Esta pesquisa caracterizou-se como um estudo descritivo analítico-comparativo quantitativo e qualitativo. $\mathrm{O}$ instrumento utilizado foi uma adaptação do questionário ROSE, aplicado com estudantes universitários ingressantes e concluintes do curso de Ciências Biológicas - Licenciatura e Bacharelado da UFSM, no ano de 2013. Participaram deste estudo, ao total, 66 acadêmicos.

Para a análise dos dados utilizou-se o Teste de Kolmogorov-Smirnov para testar a normalidade $(p>0,05)$ dos dados e, posteriormente, através do Teste não paramétrico U de Mann-Whitney, compararam-se as médias das respostas de ingressantes e concluintes, a fim de identificar possíveis diferenças estatísticas significativas $(p<0,05)$. Calcularam-se as estatísticas descritivas, tais como média e desvio padrão das respostas, para fazer inferências a cerca dos resultados obtidos com o teste U. Os dados foram analisados através do Software Statistical Package for Social Science (SPSS)- versão 17.0.

A pesquisa conta com a aprovação do Comitê de Ética da Instituição e, também, com o consentimento da coordenação, dos docentes e dos discentes do curso. Vale 
ressaltar que esta investigação vem sendo desenvolvida na UFSM com o curso de Ciências Biológicas desde 2011 com ingressantes e concluintes, com o intuito de traçar um perfil dos alunos formados pela instituição a partir da percepção dos investigados. Um estudo com os resultados parciais desta pesquisa, abordando os três anos pesquisados (2011, 2012 e 2013), foram apresentados no Encontro Nacional de Pesquisa em Educação em Ciências (ENPEC) no ano de 2013, intitulado: The Relevance Of Science Education (ROSE): tecendo um perfil a partir da voz de alunos ingressantes e concluintes de ciências biológicas da Universidade Federal de Santa Maria (UFSM/RS) em relação à temática meio ambiente (AMESTOY et al, 2013). Desta forma, em 2014 ter-se-á acompanhado o processo de formação inicial da primeira turma de ingressantes que responderam ao questionário no ano de 2011.

\section{Resultados e discussão}

\subsection{Perfil dos envolvidos na pesquisa}

Constatou-se que, dos 66 acadêmicos participantes do estudo, $39(59,1 \%)$ representam os estudantes ingressantes, sendo $25(37,9 \%)$ do gênero masculino e $14(21,2 \%)$ do gênero feminino. Representam os concluintes 27 (40,9\%) estudantes, sendo 16 (24,2\%) do gênero masculino e 11 $(13,7 \%)$ do gênero feminino. Considerando o ingresso anual de 44 estudantes (GUIA DE CURSOS - UFSM, 2013) e a baixa evasão do curso, se tem um número quase integral dos potenciais envolvidos na pesquisa. Os questionários foram aplicados durante aulas regulares do curso, sendo os alunos presentes esclarecidos sobre os objetivos da pesquisa e convidados a respondê-la.

A estatística descritiva, quanto às idades (em anos), estão apresentadas na tabela 1, levando-se em consideração os dois grupos de acadêmicos. Sendo a média geral das idades de 19,86 anos com um desvio padrão $\left(\mathrm{DP}^{*}\right)$ de 2,739 .

Tabela 1: Estatística descritiva da idade dos estudantes

\begin{tabular}{ccccccccc}
\hline \multirow{2}{*}{ Ano } & \multicolumn{4}{c}{ Ingressantes } & \multicolumn{4}{c}{ Concluintes } \\
\cline { 2 - 8 } & Mínimo & Máximo & Média & DP* & Mínimo & Máximo & Média & \multirow{2}{*}{ DP* } \\
\hline 2013 & 17 & 29 & 18,69 & 2,597 & 20 & 27 & 21,56 & 1,968 \\
\hline
\end{tabular}

\subsection{A escala de Likert e as opiniões dos uni- versitários sobre Ciência e Tecnologia}

Antes de nos determos aos resultados da pesquisa, explicaremos brevemente a escala de Likert do instrumento ROSE, a qual é composta por quatro pontos, diferentemente de outras que, geralmente, são formadas por cinco pontos. De acordo com Tolentino-Neto (2008, p. 63):
[...] há muito debate sobre a quantidade de opções incluídas na escala Likert: enquanto o uso de cinco opções (ou qualquer outro número ímpar) permite que haja - no centro - uma posição "neutra", esta mesma posição pode servir de amparo aos alunos menos envolvidos com a pesquisa, expressando falta de entendimento, indiferença, recusa etc. A escala de quatro pontos também é utilizada no PISA o que conta a favor dos defensores do ROSE.

Para Schreiner (2006, apud TOLENTINO-NETO, 2008 , p.63) a escala de quatro pontos "força" o aluno a se posicionar e o eventual aspecto ético sobre esta pressão (afinal o aluno tem o direito de permanecer neutro, de não se posicionar) é aliviado quando, na introdução do instrumento e de cada uma de suas seções, lhe é permitido deixar os itens sem respostas.

O ROSE está dividido em seções, sendo a seção $G$ do instrumento "As minhas opiniões sobre a Ciência e a Tecnologia" que fica com suas opções de resposta organizadas entre 1 (Não concordo) e 4 (Concordo). Desta maneira, "o nome dado às frações da escala também é importante: no ROSE optou-se por apenas nomear os extremos da escala (pontos um e quatro) evitando a tarefa de se criar (e depois traduzir) títulos para os pontos intermediários" (TOLENTINO-NETO, 2008, p. 63).

A opção desta escala de Likert torna mais clara a compreensão dos resultados. Os resultados das afirmativas investigadas encontram-se na tabela 2.

Tabela 2: "As minhas opiniões sobre a Ciência e a Tecnologia"

\begin{tabular}{cccc}
\hline \multirow{2}{*}{ Variáveis } & \multicolumn{2}{c}{ Média/ Desvio padrão } & \multirow{2}{*}{ P } \\
\cline { 2 - 3 } & Ingressantes & Concluintes & 0,049 \\
\hline $\begin{array}{c}\text { A ciência e tecnologia ajudarão a } \\
\text { erradicar a pobreza e fome no mundo }\end{array}$ & $2,30 / 0,770$ & $1,92 / 0,929$ & \\
$\begin{array}{c}\text { A ciência e tecnologia podem } \\
\text { resolver quase todos os problemas }\end{array}$ & $2,27 / 0,839$ & $1,79 / 0,833$ & 0,005 \\
$\begin{array}{c}\text { Um país precisa de ciência e } \\
\text { tecnologia para se desenvolver }\end{array}$ & $3,52 / 0,667$ & $2,88 / 0,947$ & 0,014 \\
\hline
\end{tabular}

\subsection{Concepções dos universitários sobre o pa- pel e a importância da C\&T}

Com relação à primeira e à segunda afirmativa apresentada na tabela acima, percebe-se que, ao ingressar no curso, os jovens universitários não atribuem à C\&T o papel "salvacionista" para solucionar problemas (média 2,27 ) e erradicar a pobreza e a fome no mundo $(2,30)$. Já na terceira afirmativa, os discentes concordam $(3,52)$ que a $C \& T$ são fundamentais para o desenvolvimento de um país.

Os concluintes, por sua vez, seguem na mesma linha de pensamento dos ingressantes com relação à primeira, à segunda e à terceira afirmativa, no entanto, em níveis 
de escala Likert, estes mostram-se mais pessimistas com relação a C\&T contribuir para o desenvolvimento do país $(2,88)$ e, consequentemente, solucionar os problemas da sociedade $(1,79)$.

\subsection{A 'voz universitária'}

Como o objetivo deste estudo é traçar um perfil comparativo sobre as concepções de ingressantes e concluintes sobre alguns aspectos relacionados à C\&T, constatou-se, por meio de análises estatísticas, que existe uma diferença significativa entre os universitários investigados (Tabela 2). Isto é, os resultados indicam que os alunos concluintes do curso de Ciências Biológicas, quando comparados com os ingressantes do mesmo curso, apresentam um posicionamento menos otimista sobre C\&T e suas influências na sociedade.

De acordo com os investigados, para um país se desenvolver é necessário C\&T, embora não identifiquem suas contribuições para solucionar alguns problemas da sociedade (pobreza, fome etc). Segundo Santos e Mortimer (2002), debates em torno das aplicações da C\&T no cotidiano estão se intensificando, pois os seus reflexos/ resultados na sociedade estão longe dos esperados. Para os autores supracitados (p.02):

As sociedades modernas passaram a confiar na ciência e na tecnologia como se confia em uma divindade. [...] Como conseqüência do cientificismo que emerge desse processo, a supervalorização da ciência gerou o mito da salvação da humanidade, ao considerar que todos os problemas humanos podem ser resolvidos cientificamente.

Segundo Auler e Delizoicov (2001), esta visão é denominada de Perspectiva Salvacionista da Ciência e Tecnologia, ao considerar que "o desenvolvimento científico gera desenvolvimento tecnológico, este gerando o desenvolvimento econômico que determina, por sua vez, o desenvolvimento ou bem-estar social" (p.04). Para os autores, isto parte de uma visão equivocada, linear e neutra do progresso da C\&T.

Considerando que a ciência não é neutra, Angotti e Auth (2001) salientam que os avanços tecnológicos na teoria visam melhorar as condições de vida das pessoas, no entanto, o que se presencia é que por meio da $C \& T$ estas populações continuam sendo desfavorecidas. Isto por que, conforme os autores:

Está cada vez mais evidente que a exploração desenfreada da natureza e os avanços científicos e tecnológicos obtidos não beneficiaram a todos. Enquanto poucos ampliaram potencialmente seus domínios, camuflados no discurso sobre a neutralidade da C\&T e sobre a necessidade do progresso para beneficiar as maiorias, muitos acabaram com os seus domínios reduzidos e outros continuam marginalizados, na miséria material e cognitiva (p.16).
Desta forma, consideramos que os universitários do presente estudo, principalmente os concluintes, apresentam uma percepção coerente e realista com o que presenciamos em nosso cotidiano. No entanto, o perfil desejado do egresso do Curso de Ciências Biológicas, seja bacharel ou licenciado, é saber estabelecer relações entre ciência, tecnologia e sociedade, atendendo o mercado de trabalho com uma visão ética e humanística (GUIA DE CURSOS, 2013).

Desta forma, nos questionamos: qual seria o posicionamento humanístico e ético dos futuros biólogos para atender ao mercado de trabalho capitalista, se para estes a C\&T só serve para desenvolver o país, mas que este desenvolvimento pouco contribuirá para a melhoria de vida dos desfavorecidos? A partir deste questionamento, surge outra questão: qual é a concepção de C\&T dos universitários?

Indagamo-nos quanto a isto, pois segundo Santos e Mortimer (2002) a ciência t tecnologia geralmente é reduzida apenas aos seus aspectos técnicos. Para os autores, é necessário ir além dos aspectos técnicos (p.09):

A identificação dos aspectos organizacionais e culturais da tecnologia permite compreender como ela é dependente dos sistemas sociopolíticos e dos valores e das ideologias da cultura em que se insere. É com esse entendimento que o cidadão passa a perceber as interferências que a tecnologia tem em sua vida e como ele pode interferir nessa atividade [...] É a partir da identificação dos valores que se compreendem melhor as necessidades da sociedade e os aspectos éticos que devem ser considerados no uso mais responsável da tecnologia.

Para isso, percebe-se que C\&T deve ser abordada desde seus aspectos técnicos até os culturais, sociais, econômicos, pois sem explorar estas dimensões, seu compreendimento fica fragmentado e comprometido. Sobre isso, destacamos que o curso de Ciências Biológicas da UFSM tem duração de oito semestres. Neste período os universitários devem cursar 46 disciplinas para obter as duas habilitações (licenciatura e bacharelado). Porém, cabe aqui levantar a discussão sobre quais concepções de ciência estão sendo difundidas para que esses universitários - profissionais responsáveis por lidar com questões desse gênero - concluam o curso menos crédulos em mudanças e melhoras do que quando ingressaram no curso. Mais realistas ou mais pessimistas.

Podemos refletir sobre um modelo de educação centrado apenas em conteúdos e fórmulas. Santos e Mortimer (2002, p.08) batizaram este modelo de:

[...] ensino do cotidiano, que se limita a nomear cientificamente as diferentes espécies de animais e vegetais, os produtos químicos de uso diário e os processos físicos envolvidos no funcionamento dos aparelhos eletroeletrônicos. Um ensino que contemple apenas aspectos dessa natureza seria, a nosso ver, puramente enciclopédico, 
favorecendo uma cultura de almanaque. Essa seria uma forma de "dourar a pílula", ou seja, de introduzir alguma aplicação apenas para disfarçar a abstração excessiva de um ensino puramente conceitual, deixando, à margem, os reais problemas sociais.

Desta forma, percebemos, com essa pesquisa, que o perfil desejado talvez não seja o alcançado ao longo do processo formativo. Por isso, tentamos traçar algumas hipóteses para entendermos 'a voz' desses universitários. Uma das hipóteses são as discussões e reflexões entre docentes e discentes a respeito de concepções sobre ciência, tecnologia, educação e política durante as disciplinas cursadas. Para Araújo e Bizzo (2005) o professor tem, sob o pensar, a responsabilidade de formular ementas que serão transformadas em disciplinas e, assim, propiciar discussões que conduzam os acadêmicos a construir suas identidades profissionais. Conforme Nóvoa (2007, p.16) “a identidade não é um dado adquirido, não é uma propriedade, não é um produto. A identidade é um lugar de lutas e de conflitos, é um espaço de construção de maneiras de ser e estar na profissão".

Outra hipótese é a ausência de um currículo que conecte conteúdos entre pesquisa e prática. Schön (1992) analisa, criticamente, a formação da própria prática profissional. Ele defende que a lógica da formação está ligada à racionalidade técnica na qual a prática situa-se ao final do currículo, desconsiderando o seu processo de reflexão. Além disso, a identidade profissional desses universitários é construída - ao longo de sua jornada formativa - por meio de participação de eventos dentro e fora da instituição, perpassando pelo amadurecimento natural e inerente ao estudante universitário, entre outros.

Segundo Tolentino-Neto (2008, p.32) "cada vez mais decisões são tomadas baseadas na ciência. Um indivíduo bem informado posiciona-se em confrontos de opiniões que constitui a base da democracia". Desta forma, Santos e Mortimer (2002, p.09) salientam que:

Não se trata de simplesmente preparar o cidadão para saber lidar com essa ou aquela ferramenta tecnológica ou desenvolver no aluno representações que o instrumentalize a absorver as novas tecnologias. Tais conhecimentos são importantes, mas uma educação que se limite ao uso de novas tecnologias e à compreensão de seu funcionamento é alienante, pois contribui para manter o processo de dominação do homem pelos ideais de lucro a qualquer preço, não contribuindo para a busca de um desenvolvimento sustentável.

Diante disso, é reforçada a necessidade de discussões a cerca dos currículos vigentes nas universidades e as identidades profissionais que estão sendo construídas no decorrer de seus cursos. Não só os currículos universitários, mas os vigentes também na educação básica são engessados a um processo de ensino conteudista, ausente de reflexões contextualizadas e conexões entre teoria e prática, academia e sociedade. Desfavorece, dessa maneira, as inter-relações que podem ser estabelecidas entre os conteúdos didáticos e os problemas enfrentados pelas sociedades.

\section{Considerações finais}

Em uma sociedade do século XXI, dar a voz aos estudantes é muito oportuno, uma vez que se compreendem os motivos pelos quais os estudantes de hoje, futuros profissionais, tomam (tomarão) algumas atitudes. Neste sentido, consideramos que o instrumento aqui utilizado pode ser aplicado para qualquer curso ou grupo de pessoas de diversas faixas etárias, sempre que necessário realizando adaptações, pois a C\&T está presente em nossas vidas e deve ser levada em consideração no que diz respeito ao desenvolvimento da sociedade.

As concepções dos universitários ingressantes e concluintes nos possibilita desenhar um perfil dos futuros biólogos baseado em suas expressões. Podemos dizer que ao ingressar no curso, esses universitários mostram-se relativamente otimistas quanto às suas crenças e opiniões sobre as questões que envolvem ciência e tecnologia e aos seus benefícios. No entanto, prestes a deixar a universidade e ingressar no mercado de trabalho, nota-se uma mudança de pensamento, ou seja, tais universitários tornam-se menos otimistas com relação às mesmas questões.

Neste sentido, a identidade profissional está intrinsecamente ligada aos processos ocorridos durante a formação acadêmica e, desta forma, sugere-se uma reestruturação curricular que envolva uma teoria fundamentada em uma prática que busque estabelecer relações com a sociedade para além dos conteúdos técnicos da profissão, reestabelecendo elos entre a educação formal e os problemas sociais.

\section{Agradecimentos}

Agradecimentos à Universidade Federal de Santa Maria (UFSM/RS) e ao colaborador Vinicius Pinheiro Nunes pelo trabalho estatístico.

\section{Referências}

AMESTOY, M. B. et al. The Relevance Of Science Education (ROSE): tecendo um perfil a partir da voz de alunos ingressantes e concluintes de ciências biológicas da Universidade Federal de Santa Maria (UFSM/RS) em relação à temática meio ambiente. In: IX Encontro Nacional de Pesquisa em Educação em Ciências. 2013, Águas de Lindóia - São Paulo. Anais...Águas de Lindóia, 2013. 
ANGOTTI, J. P; AUTH, Milton Antonio. Ciência e Tecnologia: Implicações sociais e o papel da Educação. Ciência \& Educação, v.7, n.1, p.1527, 2001.

AULER, D.; DELIZOICOV, D. Alfabetização científico-tecnológica para quêm?. Ensaio Pesquisa em Educação em Ciências, v. 3, n. 1, jun, 2001.

AULER, D; DELIZOICOV, D. Ciência-TecnologiaSociedade: Relações estabelecidas por professores de ciências. Revista Electrónica de Enseñanza de las Ciências, Barcelona, v. 5, n. 2, p. 337-355, 2006.

FREIRE, P.Conscientização: teoria e prática da libertação. São Paulo: Ed Moraes, 1980.

GUIA DE CURSOS. Universidade Federal de Santa Maria. 2013. Disponível em:

http://www.coperves.ufsm.br/concursos/ vestibular_2013/arquivos/vestibular_2013_guia_de_ cursos.pdf.Acesso em: 04 jan 2014.

JENKINS, E.W. The Student Voice and School Science Education, Studies in Science Education, 42, p. 4988, 2006.

NÓVOA, A. Os professores e as histórias da sua vida. In: NÓVOA, A. (Coord). Vida de professores. $2^{\circ} \mathrm{Ed}$. Portugal: Porto, 2007. p.11-30.

OGAWA, M; SHIMODE, S. Three Distinctive among japanese students in terms of shchool science preference: from preliminary analysis of japanese data of an internacional survey 'The Relevance os science Education' (ROSE). Journal of Science Education in Japan, vol. 28. n 4, 2004.

SANTOS, W. L. P. dos; MORTIMER, E. F. Uma análise de pressupostos teóricos da abordagem CTS (Ciência - Tecnologia - Sociedade) no contexto da educação brasileira. Ensaio Pesquisa em Educação em Ciências, v. 02, n 2, dezembro, 2002.

SCHÖN, D.A. Formar professores como profissionais reflexivos. In: NÓVOA, A (Coord). Os professores e a sua formação. Lisboa: Dom Quixote, p.7791, 1992.

TOLENTINO-NETO, L. C. B. de. Os interesses e posturas de jovens alunos frente às ciências: resultados do Projeto ROSE aplicado no Brasil. 2008. 172f. Tese (Doutorado em Educação) Faculdade de Educação, Universidade de São Paulo. 2008. 